\title{
7. Being a good computer professional: The advantages of virtue ethics in computing
}

\author{
Richard Volkman \\ Southern Connecticut State University
}

\section{Introduction}

When smart and well-educated professionals misbehave, ethicists have to wonder if we could have done anything to prevent it. After all, while it may be morally satisfying to simply assign full blame for the woes of Enron, Tyco, Worldcom, and others, to corrupt corporate leaders, such an analysis begs the further questions: Why did morally deficient actors rise to such prominent positions in the first place? Why were the prevailing standards, policies, and practices of professional ethics - embodied in implicit and explicit ethical controls - so unable to regulate conduct that in hindsight seems obviously beyond the pale? One plausible answer has to do with the impotence of standard utilitarian and deontological styles of reasoning, in the face of prevailing uncertainty about values and outcomes in the context of the 'new economy.' These concerns are especially acute in computer ethics; while change and uncertainty is a problem in business, it is at the very heart of computing and the circumstance that gives rise to computer ethics (Moor, 1985). In general, if one cannot rationally determine the outcomes of action or how to evaluate those outcomes, then utilitarian and deontological reasoning cannot guide action, and this leaves ample room for rationalisation, and this undermines the efficacy of these approaches to computer ethics.

In contrast, principles of good character do not derive from statements of eternal, universal values or fortuitous outcomes; a virtue is a trait of character that is good for the person who has it, where the value of good character derives from the agent's own commitments. It follows that virtue ethics is not susceptible to rationalisations based on extrinsic rewards, which are made uncertain by a prevailing relativism about values or by a volatile economic environment. An analysis of the culture of computing grounds the classical virtues of integrity, honesty, courage, and good judgement in the antecedent beliefs and values 
typical of those entering the profession. Virtue helps to flesh out the spirit of the profession, as this stands behind professional codes and other artefacts of professional ethics.

The principle aim of this paper is to introduce the educated lay reader, especially current and future computer professionals, to the basic advantages and strategies associated with the use of virtue terms in the description and prescription of ethical conduct. In light of this goal, the essay seeks to capture the main ideas that motivate a virtue- or character-centred approach to ethics, while remaining uncommitted with respect to a number of interesting theoretical and philosophical matters, including even the question of whether the thoughtful application of virtue terms to practical reasoning should be conceived as any kind of theory at all. An applied ethics of virtue is found in thinkers as diverse as Aristotle to Nietzsche, and it is not the aim of this essay to advance one or another particular approach or to address the metaphysical or epistemological doctrines that distinguish them. Virtue discourse works as a guide to action, no matter how these foundational questions should turn out, and that may be the principle advantage of the virtue ethics approach to applied ethics. If this essay succeeds in showing that there are good reasons to become fluent in the language of virtue, then a further examination of the particular accounts of virtues, and whether virtue ethics is an alternative ethical theory or an alternative to ethical theory, can be fruitfully explored.

\section{Problems in applying an ethics of rules and outcomes}

At least when applied to the contexts of professional ethics, utilitarian and deontological ethics generally boils down to a concern for good outcomes, on the one hand, or obedience to good rules on the other. This way of thinking about ethics is problematic, however, especially in a cultural and economic context characterised by relativism and uncertainty. Relativism about values and uncertainty about outcomes straightforwardly undermine any utilitarian calculus as a guide to action. One cannot choose the course of action that will generate the best outcome if one has no standard for evaluating outcomes and no means of predicting outcomes. The situation is little better for deontology. If morality is ultimately about acting on the right rules of conduct, then one cannot figure out how to behave morally unless one is able to determine what the right rules are and how they apply to a given circumstance. But conditions of change call established rules into question and can blur the lines between appropriate and inappropriate application of the rules. To offer a concrete example, no deontologist (except perhaps for Kant himself) would maintain that 
it is always wrong to lie. In the context of a perceived 'new economy', it is a short leap to the view that 'creative' accounting is not really lying, or, if it is lying, then it is not a case where lying is wrong. After all, the stock just keeps going up.

Of course, this is plainly mere rationalisation. Utilitarian and deontological styles of reasoning, however, invite this sort of rationalisation. In both cases, an illusion of ethical precision combined with the notion that ethics is a constraint on one's self-interest creates an incentive to find ethical loopholes. Even if professional philosophers can discern something amiss in this characterisation (and I do mean if), it is plain enough that business leaders and other professionals could get this impression. Whatever one thinks about the ultimate grounds of ethics, the point here is that ethicists need to talk about and emphasise something more than rules of conduct and calculations of the overall good. If morality seems to be nothing but a bunch of rules or calculations that operate against what I would really like to do, and if certain clever considerations seem to show that a given rule does not apply in this particular case, then there is a strong incentive to be overly clever. This encourages a lawyerly approach to ethics that is quite at odds with the spirit of utilitarian or deontological morality, but entirely predictable if morality is reduced to good outcomes and right rules. If one tinkers with the calculation or evaluation of outcomes, or if one fuzzes the rules or their application, then just about anything goes. And the tinkering and fuzzing do not require willful fudging by the agent. In our current cultural, economic, and technological circumstance, transformative change does this all by itself.

Of course, all this applies to the world of computing even more plainly than the world of business. Jim Moor's seminal 'What is computer ethics?' identifies the field with 'conceptual vacuums' that give rise to 'policy vacuums' as a consequence of 'the transformation of social institutions' attributable to the introduction of computing (Moor, 1985). Against this, Don Gotterbarn has argued that an overbroad conception of computer ethics is 'unmanageable' and that it makes for 'unsolvable problems', while appealing to the uniqueness or transforming effect of computing distracts the field from its proper focus on professional ethics (Gotterbarn, 1991). In this connection, Gotterbarn and others have emphasised the importance of articulating the nature and morality of computing as a profession, culminating in the drafting of the 'Software Engineering Code of Ethics and Professional Practice' by a joint task force of the IEEE and the Association for Computing Machinery (ACM).

But it has to be acknowledged that the difficulties noted above for utilitarian and deontological ethics apply to the creation and application of a code of ethics (which is, after all, an essentially deontological enterprise). If a code of ethics encourages professionals to think of ethics as reduced to a collection of rules, 
then lawyerly rationalisations are encouraged, especially insofar as relativism and change undermine the authority of any particular rule or its application. In this vein, John Ladd worries that, 'a code of ethics can be used as a cover-up for what might be called basically "unethical" or "irresponsible" conduct' (Ladd, 1980). In anticipation of this concern, the IEEE/ACM code explicitly rejects reading the code as a moral checklist. The preamble asserts:

It is not intended that the individual parts of the Code be used in isolation to justify errors of omission or commission. The list of Principles and Clauses is not exhaustive. The Clauses should not be read as separating the acceptable from the unacceptable in professional conduct in all practical situations. The Code is not a simple ethical algorithm that generates ethical decisions. In some situations, standards may be in tension with each other or with standards from other sources. These situations require the software engineer to use ethical judgment to act in a manner that is most consistent with the spirit of the Code of Ethics and Professional Practice, given the circumstances.

Of course, this leads one to wonder how to identify the 'spirit' of the code. The answer seems to lie in the genealogy of the code itself: 'As this Code expresses the consensus of the profession on ethical issues, it is a means to educate both the public and aspiring professionals about the ethical obligations of all software engineers' (IEEE/ACM Joint Task Force, 1999).

This suggests that the spirit of the IEEE/ACM code can be understood as the consensus of the profession on ethical matters. Before joining the task force, Michael Davis had argued 'a code of ethics is primarily a convention between professionals. According to this explanation, a profession is a group of persons who want to cooperate in serving the same ideal better than they could if they did not cooperate' (Davis, 1992). The moral force of the code, in this view, comes from its being the articulation of the considered judgement of those in the profession about the best way to achieve the values that define the profession. Engineering, for example, is about 'the efficient design, construction, and maintenance of safe and useful objects,' and the values embedded in this description of what engineering is about characterise what it means to be 'thinking like an engineer' (Davis, 1992). The code of ethics expresses the culture of the profession, and the process whereby that culture is articulated in a written form is normatively more important than the precise articulation of the rules or values in the artefact itself. The culture that animates the code identifies the 'spirit' of the code.

This account goes a long way towards resolving the main problems, noted above, for utilitarian and deontological ethical approaches. But one needs to see that the solution is the result of abandoning stereotypical deontological and utilitarian modes of thinking in favour of 'thinking like an engineer'. Instead of specifying 
the rules of right conduct, the antecedent culture identifies values that generate reasons for action, even in the absence of clear rules of conduct. Moreover, the authority of the culture need not be asserted as expressing categorical judgements of value. Relative assertions will do just fine. The normative force of the code is settled, at least within the practice of engineers, by correctly noting: 'This is who we are; this is what we value; this is how we achieve our goals.'

This, however, raises a number of questions. Some have to do with making the account more clear: Where the particular principles and clauses of the code break down, how does one guide action? That is, how can one articulate the spirit of the code when its deontological formulation is questioned? What are the units for such an analysis? What are the terms of debate when the spirit of the code is itself in dispute? Other questions have to do with the evaluation of the written code: Does this code actually express the culture of the profession? Is that culture worthy of expression in a code? Some of these issues turn on an empirical description of the culture, while others demand normative and conceptual clarification. Both sorts of concerns will be addressed below with respect to the profession of computing. What we find is that the space 'between the lines' of the code is populated by virtue, and that virtue terms can adjudicate and articulate moral debate without the problems identified for utilitarianism and deontology.

\section{The culture of computing}

By a culture, I mean 'the values, attitudes, beliefs, orientations, and underlying assumptions prevalent among people in a society' (Huntington, 2000). The relevant 'society' in this context consists especially of those 'involved in the design and development of computer artifacts' (Gotterbarn, 1991), but it also extends to those consumers of computer artefacts who identify with technology as an integral part of their lives. In short, I hope to identify something of the culture of 'computer geeks.' That there is such a culture, antecedent to philosophical theorising about professional ethics, is indicated by the fact that everyone has a sense of who the 'computer geeks' are, just as surely as one has a sense of who is meant by 'hippies' or 'Bible-thumpers'. It is significant that there is no similar sense of who is picked out by 'telephone enthusiasts' or 'pealovers.' While plenty of people like telephones, no-one seems much interested in evangelising for them, and people who like telephones probably have very little else in common. This explains why there is no such thing as 'telephone ethics', despite the transforming effect of telephones on society. Telephones do not represent a way of life. Things differ in important ways in computing. 
Computer technology does have evangelists, and those who embrace computing sufficiently share values and beliefs such that they represent a coherent social unit.

On the other hand, as with hippies or Bible-thumpers, there are a host of subcultures and competing assumptions among computing enthusiasts. Furthermore, social categories routinely overlap. Some computer geeks are Bible-thumpers, and some computer geeks are hippies. Fortunately, it turns out that these complications have very little impact with respect to the main thesis of this essay. If an appeal to the core values of geek culture is sufficient to ground the virtues, then it is proved that geek culture combined with Evangelical Christianity or tree-hugging environmentalism is sufficient to ground the virtues. It is left open whether these combinations can be coherent and sustained. While I am sure there is good reason to have other commitments as well, the purpose of this essay is simply to see how much ethical content can be gleaned from the culture of computing by itself. For that purpose, what matters is whether the spirit of professional ethics can be articulated in terms any computer enthusiast would have to grant simply in virtue of being a computer enthusiast.

The reason for focusing on the culture of the enthusiast instead of what might be the more enlightened or elevated culture of mature computer professionals stems from the educational function of professional ethics, and especially the IEEE/ACM code. (IEEE/ACM, 1999) Appealing to the judgements of mature members of the profession amounts to little more than preaching to the choir, unless it can be shown that these judgements are implied by the antecedent aspirations of the intended audience. Insofar as professional ethics is for the enculturation of new members to the profession, arguments for more mature attitudes must appeal to attitudes already consonant with those of prospective professionals. Students who aspire to become computer professionals are typically motivated by either the promise of a lucrative career in computing, or an antecedent enthusiasm for technology (or both). Enthusiasm for money has little to do with computing, per se; enthusiasm for technology, however, obviously does. As we shall see, an analysis of the virtues (especially integrity) shows that mere enthusiasm for wealth is problematic as a way of life, even on its own terms; but if it is demonstrated that the values of the profession can be conceived as the mature expression of enthusiasm for technology, then one important category of serious students can be motivated to think professionally. The bottom line is that a successful education needs to start where the students are, and an important category of students has already embraced geek culture.

It may seem that mere enthusiasm for technology is too squalid as a way of life to ground ethical judgements. A closer look at the cultural artefacts and selfreflecting essays of geek culture, however, reveals values that amply serve as 
raw material for a more substantive ethics. The assertion that 'Technology is cool' expresses an evaluation that connects with a wide range of other values and ultimately grounds a coherent conception of the good life.

Wired magazine features a monthly department titled, 'Fetish: technolust'. In this department, cool new gadgets and technologies are described alongside fullcolour glossy photos. Sometimes the descriptions make it clear why the editors believe a featured device is desirable enough to be compared to the erotic, but most of the time it suffices to simply describe what it does. The audience of Wired does not need to be told what makes something cool. However, such judgements need not be inarticulate. In fact, just the opposite is the norm. Product reviews are surely among the most ubiquitous of written artefacts in geek culture. They are found in magazines like Wired, MacWorld, SysAdmin, PlanetPDA, and PCWorld; they are the foundation of huge and famous websites like Tom's Hardware Guide, and they are regular subjects of debate on Slashdot. For the ethicist or cultural anthropologist, what is significant about product reviews is that they express evaluations based on the common values that help to define the culture. In this context, the fact that Wired can simply display certain items as obviously worthy of technolust demonstrates the extent to which these values can be taken for granted, at least among members of the culture. The coolness of some objects does not need to be demonstrated; it is observed.

Judging that a gadget is cool is in large measure an aesthetic judgement. This aesthetic is exemplified in the behaviour of a high-school friend who used to compete in computer programming contests at a nearby engineering college. These events were typically followed by a small trade show where technology and engineering companies would display their latest work in the hopes of attracting future employees. (Note, they displayed their works; they did not advertise salaries). My friend discovered at one of these shows a mini-switch that completely captivated him. These switches were nothing special to look at, but he loved the solid, sturdy feel in such a small device, and especially the tactile and auditory feedback it gave the user. When one clicked the button, one knew instantly whether the thing had switched. Clickety-click. He handed one to me, beaming with the same expression a singer friend wore at his first Broadway musical. Clickety-click. 'This is a nice switch,' he gushed. Clicketyclick. For weeks after, he carried a pocketful of these switches with him, absentmindedly clicking them in satisfaction as he worked and played. Like most aesthetic judgements, it is hard to convey the meaning of this experience to anyone who does not already get it; it is not merely to recognise but truly to appreciate quality craftsmanship and clever technical solutions to ordinary problems, the way one might appreciate a painting in a museum or a music performance. 
I submit that this appreciation reflects a judgement - experienced by the initiated as an immediate observation - that the object of appreciation is a clever, elegant, well-designed, efficient, or otherwise powerful solution to some technical puzzle. It is in these terms that product reviews tend to extol or disparage their objects, and it is in these terms that debate rages about the merits and demerits of competing operating systems, chip architectures, or industrial design solutions. To be a computer geek is to be fluent in this language, and it is a language of values with implications beyond what kind of computer to buy.

Many of these enthusiasts aspire to go beyond being connoisseurs of technology and to design and create their own solutions. These are the students we are trying to reach in courses about professionalism in computing, and it is fortunate for us that they are already embedded in a way of life receptive to talk of objective evaluations. From this commitment stem the other main hallmarks of geek culture, especially their commitment to reasoning and justification. In the world of technology, reasoning and know-how matter; mere appeals to authority are worthless. This is evident in any serious debate on Slashdot, where the argument is not settled until detailed references are provided. Usually, this takes the form of links to other sites, so each participant can be satisfied about the validity of the claims. As in academic debate in other venues, however, these discussions usually are not settled but are met with competing arguments and data, similarly referenced.

This commitment to reasoning and justification in debate also indicates that members of the community are generally self-navigating and resistant to leadership or indoctrination. To substantiate one's case by linking to external documentation so anyone can examine the data for herself only makes sense in a community whose members insist on thinking for themselves. As Jon Katz has amply documented, the online community does not tolerate self-proclaimed leaders and does not promote leaders of its own. For geeks, mainstream symbols of authority and prestige are suspect, while scientists, technologists, and others who routinely defend their claims against invited criticism, are revered (Katz, 2000). Instead of appealing to the authority of tradition or position, arguments are expected to stand or fall on their own merits, with the further expectation that the very best arguments will withstand withering criticism and scrutiny from the community at large and ultimately emerge as the prevailing view. Geek culture thus embodies an instinct for Popperian scientific method and the marketplace of ideas. In contrast to following authoritative leaders, the geek community sees itself as tracking truth, guided by the invisible hand of reason. There is a palpable and sometimes snide impatience with those who will not or cannot justify their claims, as one Slashdot article makes explicit: 'This is the 
story of one computer professional's explorations in the world of postmodern literary criticism. Wouldn't it be nice to work in a field where nobody can say you're wrong?'

The idea that there is a best way of doing things and that we can learn what it is through a process that rationally filters and evaluates distributed knowledge grounds an optimistic belief in technological progress. The notion of progress is controversial among some social scientists, but progress is obvious to tech enthusiasts because they experience it daily. It is manifest that the computers, cell phones, cameras, and other gadgets they work and play with today are much better than the ones they worked and played with just a few years ago. Everything has gotten faster, more powerful, smaller, cleverer, more efficient, etc. Clickety-click. If things outside of technology and engineering have not been improving at the same rate, it is because 'they' (the non-geeks who dominate mainstream society) are too stupid, cowardly and sheeplike to submit their ideas to the processes of rational scrutiny and justification that generate real progress. This commitment to progress implies an embrace of change that is nicely captured by the conclusion of Wired's montage, 'Change is good': next to a photo of burning man reads the caption, 'The future is in Beta' (Rossetto et. al., 1998).

This commitment to progress helps to ground a coherent and ethical way of life in geek culture because it permits members of the community to conceive of their lives in the manner of a 'quest.' Practical optimism and progress imply that things can be made better and that technologists are on the front lines of making it happen. They are the solution to whatever might be the problem. Moreover, those who participate in the tech community are each playing a role in making things better simply by actively participating in the process that generates and regulates technological change. This notion that embracing the process of technological change can ground a coherent life plan is perhaps best illustrated by Steve Jobs' legendary wooing of Pepsi CEO John Sculley to serve as CEO of Apple: 'Do you want to sell sugar water for the rest of your life, or do you want to change the world?' Geek culture wants to change the world, or at least surf the wave of technological change to a better life. This is the quest of geek culture and, as Alasdair MacIntyre notes, making sense of one's life in terms of a quest is the hallmark of a way of life that can ground the virtues (MacIntyre, 1984).

\section{The analysis of character}

To speak of one's character is to talk about who one is. Describing a person's character identifies him or her in terms of the values, beliefs, projects, 
commitments, and ordinary ways of reacting to the world that explain and justify his or her behaviour. We routinely rely on traits of character to predict behaviour and to thereby justify reliance. For example, we say, 'He is a hardworking fellow. I'm sure he'll get the job done.' And to be sure, the fact that he is a 'hard-working fellow' is among the reasons he was entrusted with the task in the first place. Evaluations of character are standard practice in everyday life - probably more common and useful than evaluations of action. Both positive terms like 'sweety', 'cool', and 'upbeat'; and epithets like 'creep', 'jerk', 'putz', or 'bonehead' are all evaluations of character in the sense that they speak to the being of the person evaluated rather than his or her actions. The ethical terms of everyday life - in contrast to the stuffy and stilted evaluations of academic philosophy - are aretaic, not deontic. Notice that these evaluations and our reliance on them to predict and explain behaviour assume that traits of character are relatively immutable and deep. For this reason, any agent will have to take evaluations of her own character very seriously, whatever her particular projects and other pursuits might be.

Character is typically analysed and evaluated in terms of the virtues. By a virtue is meant any trait of character that is good for the agent who manifests it, while a vice is a character trait that is bad for the agent. To say that a person manifests or lacks a virtue is both to describe and evaluate that person at the same time, and the description and evaluation cannot be separated without distorting the meaning of the term. As Philippa Foot notes, virtue terms are not unique in this respect. For example, one cannot understand what an 'injury' describes without also understanding that it is bad to be injured. The surgeon does not 'injure' a patient in the course of performing needed surgery, even if her actions are accurately described as 'cutting someone with a sharp knife, leaving a wound' (Foot, 1978). Similarly, one cannot gloss the descriptive meaning of a virtue or vice without understanding the normative context that would make the designation appropriate or inappropriate. For example, while honesty is the virtue related to truth-telling, it would be wrong to say a person is dishonest because he told a client that last minute changes to a project will be 'no problem'. It is surely not a mark of bad character that a person takes challenging clients in stride. Even though his utterance is not the whole truth, dishonesty does not describe everyone who makes an untrue statement. For proper use of the term, the evaluation matters as much as the description.

So we need to get clear about the evaluative content of the virtues as well as their descriptive components. In the Aristotelian tradition, when thinking of the virtues it is helpful to put things in terms of the Doctrine of the Golden Mean, which is a sort of heuristic for understanding the way virtue terms typically work. It must be emphasised that the Doctrine of the Golden Mean is not a principle for deducing the nature of a virtue, nor is it the last word 
in an analysis of virtue. Indeed, it is hardly the first word. It is, however, a good first step to take in organising one's thoughts about the content of our virtue terms. On the Aristotelian view, virtues describe the character of one with just the right amount of concern for some good, where the evaluative component of the virtue is unpacked in terms of the 'right amount' of concern for that good. Failures of character (vices) typically result from having either too much or too little concern for some good, and virtue is the mean between these vices of excess or deficiency. To pursue the example of honesty, truthtelling is a good. Too much concern for truth-telling, however, makes one a stickler. Being a stickler will make it hard to get along with others, thereby undermining one's pursuit of other goods like friendship or wealth. Even worse than being a stickler, however, is being dishonest, which is an even greater threat to friendships and trade relations. Even if one could be dishonest but appear honest (which is unlikely in any event), such a character could never be a good friend. Thus, anyone who recognises the value of real friendship and the relative immutability of character will have to admit the value of honesty.

While relativism about value and uncertainty about outcomes can undermine utilitarianism and deontology as guides to action, virtue terms do not derive their normative force from asserting that any particular state of affairs is categorically good. Instead, virtues relate to things that are more-or-less obviously good for me (and good for you). While there is endless debate about what is 'really' good, and what rules if any 'really' count as the categorical command of reason (or even whether there are any such rules), and while these debates are exacerbated by the various transformations wrought by the computer revolution, there is nothing mysterious or controversial about the claim that my own safety is good for me; at least, no-one generally has to be persuaded of such a claim. If I admit that safety is good for me, then I have a clear reason to manifest some concern for my own safety, and if I admit that there are other things that are also good for me, then I have a reason to manifest just the right amount of concern for safety - no more and no less. That is, I have a reason to manifest courage and to avoid being rash or cowardly. Instead of endless debate about categorical goods or uncertain outcomes, a substantive ethics emerges once one identifies the ends to which one is actually committed. Hence the Socratic dictum, 'Know Thyself!' and the Nietzschean imperative, 'Become Who You Are!'.

At a more practical level, an emphasis on character that starts from one's present commitments does not invite overly clever or lawyerly rationalisations of actions that are contrary to the 'spirit' of morality. Only a fool would expect (or try to provide) a rigorous refutation of the whole of deontological or consequentialist thought in a single paper, but it should be plain that an ethics of character enjoys very real advantages in the sphere of applied ethics. The virtue ethicist is not trying to convince anyone to abandon or limit the pursuit of her commitments 
in the name of some abstract notion of the 'moral law' or 'maximum overall net utility'. Rather, virtues are an indispensable means to success in one's own pursuits. Who does one intend to convince with lawyerly and overly clever defences? Talking one's self into bad character does the gravest harm to one's self, on one's own terms. When the ultimate judge and jury consist in the values to which one is already personally committed, the notion of 'getting away with it' loses all meaning. Getting away from whom? Yourself? How could that be a victory? Once this is understood, the more abstract and theoretical concerns of moral philosophy no longer stand in the way of applied ethics. This is especially valuable in the context of professional ethics, since an analysis of the culture and values that define the profession reveals the relevant commitments (and the ongoing terms of discussion about them within the tradition), such that 'Know Thyself!' becomes a tractable imperative.

As for guiding action, one must not misunderstand the sense in which attention to one's own character serves as a guide to action. Sometimes, utilitarian and deontological ethics have encouraged scholars to mistakenly think that a good guide to action will churn out a precise list of dos and don'ts. Against this, and echoing the IEEE/ACM code cited above, Rosalind Hursthouse notes the absurdity of thinking that ethics can be reduced to a simple algorithm that can be mastered by 'any clever adolescent' (Hursthouse, 1991). Ethics involves reflecting on the nature and meaning of life itself. It is preposterous to suppose this can be accomplished by simply doing the maths, or that it can be reduced to one or several simple rules.

Virtue ethics 'guides action' by focusing one's attention on one's striving to be the sort of person one wants to be. It asks one to reflect on who one is, and to evaluate one's own way of life in light of the sum total of one's commitments and values. Of course, not all ways of life can withstand this scrutiny. While desirable ways of life will ground virtues that form a coherent whole and confer direction and meaning to one's life, ways of life that do not imply the classical virtues are generally incoherent or otherwise undesirable. Acknowledging this presents one with an opportunity to revise one's conception of the good life and to become the sort of person one wishes to become - a person of good character, on one's own terms. When a person manifests good character, her actions flow immediately from her character in a manner akin to instinct or habit. The 'spirit' of ethics guides her action, not the letter of the law.

\section{Good character matters in the culture of computing}

Virtue ethics is illustrated by showing how the way of life associated with the culture of computing generates the virtues while close alternatives do not. As we 
shall see, this analysis makes it clear that those living by the close alternatives have good reason to adopt the culture of computing instead. As it turns out, the failure to support virtuous conduct creates serious obstacles to leading the good life, even if the good life is conceived solely on one's own terms. In contrast, the culture of computing does support virtuous conduct leading to a coherent and defensible conception of the good life. In short, advocates of the values that define the technological enthusiast will be better able to succeed in the pursuit of these values if they manifest the virtues of integrity, honesty, courage, and good judgement.

Integrity is the virtue associated with the right amount of steadfastness in one's defining values, goals, and other commitments. Just as the integrity of a building is given by its structural soundness, the person of integrity stands firm and true. Being pig-headed, narrow, or stubborn are vices of excess with respect to steadfastness, while one who is flighty, unserious, or inconstant is deficient in this good. In contrast, the person of integrity is open to criticism and will change her course as necessary, but only in light of good reasons and due deliberation. The person of integrity can be relied on to be who she is in spite of temptations or distractions. As one slogan has it, 'Integrity is doing the right thing even when no-one is looking.' The person of integrity does what she does because that is what she is all about, not because somebody might or might not be looking.

For the culture of computing, integrity involves conceiving one's life as a quest in pursuit of technological progress and embracing the practices and social institutions necessary for that pursuit. One does not manifest integrity if one behaves in a manner that will undermine the success of one's core projects. In light of this, teaching new members of the profession to value the profession itself can be cast in terms of integrity. As scholars of technology routinely emphasise, and as contributors to Slashdot often assert, technology is a social endeavour. 'Technology consists not only of artifacts and the tools and processes needed to produce them, but also of the entire social organisation of people and materials that permits the acquisition of the knowledge and skills needed to design, manufacture, distribute, use, repair, and eventually dispose of these artifacts' (Winston, 2003). Commitment to the technological project therefore issues in a commitment to the whole set of social institutions presupposed by that project. Thus, even for a computer professional who starts with nothing but an appreciation of cool technology, being true to his conception of the good requires a commitment to, among other things, the profession itself. The virtue of personal integrity hereby stands behind the IEEE/ACM code's declaration that, 'Software engineers shall advance the integrity and reputation of the profession consistent with the public interest.' 
Less obviously, the integrity of a computer professional also requires commitment to the wellbeing of end users. After all, they are an indispensable part of the social milieu of technological progress. This responds to Gotterbarn's worry that a puzzle-solving culture does not sufficiently take users into account (Gotterbarn, 1991). As conceived here, concern for the user is not an extra burden for the software engineer but an integral part of the whole pursuit. Gotterbarn is surely correct to note that those who focus on puzzle-solving are prone to overlook this. Moreover, the elitism of computer culture tends to exacerbate the problem by inspiring contempt for the ignorance and irrationality of the lowly end user. At least for those already embedded in the culture of computing, however, demonstration of the integral relation between end user satisfaction and technological progress will do more to address these concerns than any amount of finger wagging about 'service' or 'public interest.'

Honesty is closely related to integrity. As noted above, it is associated with truthtelling, and it is necessary for trade relationships and friendships of all sorts. The dishonest computer professional not only brings shame to the profession, thereby revealing his failure of integrity, but also undermines the general social circumstances necessary for the creation, implementation, and dissemination of technological solutions. Hype and marketing are not necessarily dishonest, even where such communications are not entirely frank. However, when the vague boundary between hype and fraud is crossed, progress suffers. Similarly, disseminating FUD (fear, uncertainty, doubt) about a competing product or announcing vaporware in the hopes that a potential competitor will never come to market, plainly stands in the way of technological progress. The whole point of these practices is to protect or gain a market advantage that is out of proportion to the merits of one's technology, and that plainly subverts the market's ability to adjudicate competing technologies in favour of the best solution. This analysis helps the new professional to understand why such dishonest actions are rightly denounced in the IEEE/ACM code, helping to flesh out the 'spirit' of the code.

Courage is also a virtue of the good computer professional. The willingness to embrace innovation and change is not characteristic of the coward; nor does one who is over concerned with safety submit beliefs and ideas to the rough and tumble of rational debate. On the other hand, the rash inventor or engineer will tend to make sometimes-tragic mistakes and, therefore, fail to advance technology. In geek culture, success requires real courage. In the day-to-day affairs of the good computer professional, courage reveals itself in standing up for one's ideas while submitting them to rational scrutiny. In more extreme cases, the computer professional may need the courage to blow the whistle or walk away from a project that directly or indirectly conflicts with the integrity of the profession. For example, a database of medical records that is deficient in 
security undermines the advance of technology, since any harm to the public will engender fear of similar projects in the future. Especially when money is tight or when managers do not comprehend the possible consequences of shoddy work, it can take real courage to maintain one's integrity and the integrity of the profession.

After integrity, good judgement may be the most important of the virtues since, without good judgement, the other virtues cannot be relied on to secure one's goals. If one mistakes technology for the gadgets it produces, or if one does not accurately foresee how a project might advance or undermine the goal of technological progress, then one's bad judgement will undermine one's integrity. Good judgement is difficult to characterise without circularity; one cannot merely describe good judgement in terms of getting right results, since that would leave evaluations of character hostage to fortuitous outcomes. Instead, good judgement needs to be conceived in terms of a method for arriving at right answers, and this suggests having the right amount of concern for both rational rigour and educated perception in fixing belief. Reasoning that is shallow, narrow, or short-sighted will not advance technological solutions, and may actually retard the progress of technology. On the other hand, pessimistic scepticism is directly contrary to the ethos of innovation and progress. To avoid either extreme, the good computer professional needs to develop a fine aesthetic sensibility for good design and a habit of working out problems through rational debate within a wider community. Fortunately, the resources of good judgement are at the very heart of geek culture's embrace of rationality situated in a critical community of debate and justification.

So it seems that the classical virtues can be grounded in the values of geek culture. While our discussion has only addressed a handful of the classical virtues, and only in a cursory way, it should be clear how further discussion might proceed. In general, once one has uncovered a set of values and beliefs sufficient to ground a way of life as a quest, showing how the virtues emerge from such a way of life is a trivial matter. Success in any quest will require integrity, and integrity will demand coherence and richness in one's conception of the good such that honesty, courage, good judgement, and the other virtues more or less immediately follow.

To see this, it helps to contrast the way of life of the good computer professional with close alternatives. For example, consider the way of life of the 'script kiddie'. Folks who get their kicks out of exploiting online security vulnerabilities may have a lot in common with computer geeks, and their actions may be dimly inspired by the same cultural background. It is clear, however, that script kiddies lack integrity. As the term 'kiddie' suggests, these people do not have the technological sophistication to really understand what they are exploiting. This reveals that they are not motivated by the technological aesthetic, at least 
not in any mature form. Instead, they seem to be operating on the same base motives as common vandals. Getting kicks from destroying things fails, not only in terms of geek culture, but on its own terms. The purely negative aim of destruction depends for its meaning on the work of those who create what is to be destroyed. But without some positive agenda, it is impossible to conceive one's life as a quest for something, or to evaluate one's progress with respect to what is valuable. Because their actions are entirely parasitic on the discoveries and creations of the geek community, the way of life of the script kiddie has no intrinsic meaning, and will fail as a way of life. Much the same can be said of 'crackers', who make it their business to defeat intellectual property protections and distribute expensive software packages without compensation for the authors. While this may require some technical knowhow and sophistication, 'crackers' are nonetheless parasites on the body of good computer professionals.

These failed ways of life might be contrasted with the info-terrorist or technological civil disobedient. Those who conceive themselves as fighting a guerrilla war against the perceived injustices of intellectual property rights, dangerously sloppy computer artefacts, or even the whole technological worldview might very well be on a quest. Indeed, they might even defend their actions in terms drawn straight from computer culture. 'Information wants to be free,' they might say, or, 'We exploit security flaws in technology in order to reveal them and make the technology better'. These attempted justifications of unethical conduct reveal a commitment to the values that guide the computer profession itself, and the debate is now simply about means. The consensus view among computer professionals is that civil disobedience is not the best means for advancing technology. For those who oppose the hoarding of intellectual property, participation in the creation of Free Software alternatives like Linux or OpenOffice is a more constructive and rewarding path. Security flaws can be revealed without handing the exploits over to script kiddies. The justifications of technological civil disobedience are either short-sighted or they reveal an arrogance with respect to the considered judgements of the profession and computing culture. Either way, they reflect bad judgement.

More dangerous and troubling are those who do not embrace technological culture, but who use technology as a means for other ends. Technology creates powerful tools that may be put to immoral or selfish purposes. With technical skills, con artists and other thieves can perpetrate crimes of a scale and breadth that was previously unthinkable, while maintaining an invisibility or anonymity that conceals the perpetrator or even the crime. Clearly, such crimes constitute real obstacles to the advance of technology, and it is the responsibility of the computing profession to mitigate the risks posed by those who would misuse technology. Clearly, these behaviours are not an expression of geek culture. Showing the ethical bankruptcy of the base hedonism that usually motivates 
these alternatives to computing culture is relatively straightforward. How can the hedonist, the con artist, or parasite conceive of life as a quest? Answering this question is beyond the scope of this essay, but the analysis here should indicate how reflecting on the role of character and integrity in pursuit of the good life already sketches the case to be made against those who would misuse technology, even as it fleshes out the spirit of those who create and discover it.

\section{References}

Davis, M, 1991, 'Thinking like an engineer: the place of a code of ethics in the practice of a profession', Philosophy and Public Affairs, Spring, pp 150-67.

Foot, P, 1978, 'Moral beliefs', in P Foot (ed), Virtues and vices, University of California Press, pp 110-31.

Gotterbarn, D, 1991, 'Computer ethics: responsibility regained', National Forum, Summer, pp 26-31.

Huntington, S, 2000, 'Cultures count', in L Harrison \& S Huntington (eds), Culture matters, Basic Books, pp xiii-xvi.

Hursthouse, R, 1991, 'Virtue theory and abortion', Philosophy and Public Affairs, Summer, pp 223-46.

IEEE-CS/ACE Joint Task Force, 1999, 'Software engineering code of ethics and professional practice,' online at <http://www.computer.org/cms/Computer. org/Publications/code-of-ethics.pdf $>$

Katz, J, 2000, Geeks, Broadway Books.

Ladd, J, 1980, 'The quest for a code of ethics: an intellectual and moral confusion', in R Chalk, M Frankel, \& S Chafer (eds), AAAS professional ethics project: professional ethics activities in the scientific and engineering societies, American Association for the Advancement of Science, pp 154-59.

MacIntyre, A, 1984, After virtue, University of Notre Dame Press.

Moor, J, 1985, 'What is computer ethics', Metaphilosophy 16, pp 266-75.

Rossetto, L, et al, 1998, 'Change is good', Wired, January, pp 163-207.

Winston, M, 2003, 'Children of invention,' in M Winston \& R Edelbach (eds), Society, ethics, and technology, Wadsworth, pp 1-19. 